\title{
Artificial Neural Network Modeling for Adsorption of Dyes from Aqueous Solution using Rice Husk Carbon
}

\author{
R. D. Khonde \\ Assistant Professor \\ Department of Chemical Engineering \\ Priyadarshini Institute of Engineering \& Technology, \\ Nagpur, Maharashtra State, India
}

\author{
S. L. Pandharipande \\ Associate Professor \\ Department of Chemical Engineering \\ Laxminarayan Institute of Technology, Nagpur, \\ Maharashtra State, India
}

\begin{abstract}
Adsorption is one of the important industrial processes used for removal of colour, odour, turbidity \& reduction of COD. In adsorption, the solute present in dilute concentration in liquid or gas phase is removed by contacting with suitable solid adsorbent so that the transfer of the component first takes place on the surface of solid and then into the pore of the solid.

The present work is aimed at exploring rice husk carbon as low cost adsorbent for removal of various dyes from synthetically prepared aqueous solutions and modeling the adsorption process using artificial neural network.

Rice husk carbon, developed in the present work at the laboratory scale, is analyzed for its BET surface area \& is observed to be very effective for removal of dyes, namely bromocresol red, alizarin red, malachite green and methylene blue from their aqueous solutions. Further, the RHC developed. The present work highlighted the efficacy of ANN as an effective tool in modeling adsorption.

The ANN models developed are using elite-ANN ${ }^{\circledR}$. The architecture of artificial neural network is initialized \& training has been carried out using the experimental data. The trained neural network is used to predict output for the given set of input parameters.
\end{abstract}

\section{Keywords}

Artificial neural networks, adsorption, modeling, dyes.

\section{INTRODUCTION}

The presence of dyes in effluents is a major concern due to their adverse effect to many forms of life. The discharge of dyes in the environment is worrying for both toxicological and aesthetical reasons. Industries such as textile, leather, paper, plastics, etc., are some of the sources for dye effluents. In general, dyes are poorly biodegradable or resistant to environmental conditions. Therefore it is necessary to treat the wastewaters or industrial effluents containing dyes before being discharged into the waterways. A number of chemical and physical processes such as flocculation, chemical coagulation, precipitation, ozonation and adsorption have been widely used to treat dye bearing wastewaters. However, the adsorption has been found to be superior compared to other techniques for wastewater treatment in terms of its capability for efficiently adsorbing a broad range of adsorbates and its simplicity of design. The commercially available activated carbons are still considered expensive due to the use of nonrenewable and relatively expensive raw materials such as coal, which is unjustified in pollution control applications. Therefore, in recent years, this has prompted a growing research interest in the production of activated carbons from renewable and cheaper precursors which are mainly industrial and agricultural byproducts $(1,2,3,4,5)$

An Artificial Neural Network (ANN) is an information processing paradigm that is inspired by the way the biological nervous system, such as brain processes information. It is composed of large number of highly interconnected processing elements (neurons) working in unison to solve specific problem ${ }^{(6)}$.

The most common for chemical engineering application is Multi Layer Perception (MLP), which is a feed forward neural network. It consists of multilayer hierarchical structure, which apart from input and output layers, has at least one layer of processing units in between them. The layers between the input and output layers are termed "hidden" since they do not converse with the outside world directly. The nodes between the two successive layers are fully connected by means of weights. That is outputs from the input layer are fed to hidden layer units, which in turn, feed their outputs to the next hidden nodes. The hidden node passes the net activation through a nonlinear transformation of a linear function, such as the logistic sigmoidal or hyperbolic tangent to compute their outputs. For the training of such a MLP error back propagation algorithm suggested by Rumelhart ${ }^{(7)}$ is popular. This is based on a nonlinear version of the Windro-Hoff rule known as Generalized Delta Rule (GDR). The schematic of the MLP network developed for the adsorption of dyes from aqueous solution using RHC adsorbent with two hidden layers containing five neurons each is shown in figure 1 .

Various applications of ANN are, an approach to fault diagnosis in chemical processes ${ }^{(8)}$, fault diagnosis in complex chemical plants ${ }^{(9)}$, incipient fault diagnosis of chemical process $^{(10)}$, leak detection in liquefied gas pipeline ${ }^{(11,12)}$, for estimation of mass transfer coefficient for fast fluidized bed solids $^{(13)}$, modeling of distillation column ${ }^{(14)}$, detergent formulation ${ }^{(15)}$, modeling of unsteady heat conduction in semi infinite solid ${ }^{(16)}$, prediction of mass transfer coefficient in down flow jet loop reactor ${ }^{(17)}$ and modeling of packed column $^{(18)}$ and similar other ${ }^{(19,20)}$ were also reported.

\section{MATERIALS AND METHODS}

Rice husk is synthesized into adsorbent on laboratory scale. Rice husk was first washed with water and dried in an oven at $100^{\circ} \mathrm{C}$ for about 6 hours. The material was then crushed in ball mill, sieved and burnt in furnace at $400^{\circ} \mathrm{C}$ for about 10 minutes. Number of such runs had been taken. 


\subsection{Methodology}

The present work is divided in two parts. The first part is devoted for development of rice husk carbon from an agricultural waste using thermal treatment and its analysis for measurement of surface area. The adsorption experimentation includes removal of dyes form aqueous solution, known volume of adsorbate is added to a known amount of adsorbent and once the equilibrium is reached its concentration is measured using standardized digital Colorimeter. The experimental values of $\%$ adsorption and equilibrium concentration are calculated for each adsorbate with variable amount of adsorbent as given in Table 1.

The second part is devoted for development of artificial neural network model for estimation of equilibrium concentration of different adsorbates and their \% adsorption.

\subsection{Developing ANN model}

The procedure of designing an ANN model is as follows:

- $\quad$ Specifying the number of inputs and outputs for the network

- Creating a database of specified input-output variables

- Selection of network type, number of layer, number of neurons and activation function of each layer
- Training of the network

- $\quad$ Checking the performance and precision of the trained neural network; changing and retraining of network as per accuracy level

- Validation on a set of test data

In present work, ANN model developed is using elite-ANN ${ }^{\circledR}$ ${ }^{(21)}$, a back propagation network with three inputs (adsorbate coding, initial concentration of adsorbate and adsorbent dosing), two hidden layers with five neurons each and two outputs (equilibrium concentration and \% adsorption) for prediction of concentration of adsorbate in a wide range of wavelength and optical density, shown in figure 1.

The topology of ANN architecture is as given in table 2. Table 3 shows actual and predicted values of equilibrium concentration and \% adsorption for training data set, whereas table 4 shows actual and predicted values of equilibrium concentration and \% adsorption for the test data set. For ANN modeling, each adsorbate is coded with number like 30 for bromocresol red, 60 for alizarin red, 80 for malachite green and 90 for methylene blue. The performance of ANN model is evaluated by the relative error and mean squared error (MSE).

Table 1: Total Data for ANN Modeling

\begin{tabular}{|c|c|c|c|c|}
\hline Adsorbate & $\begin{array}{c}\text { Initial } \\
\text { concentration, } \\
\mathrm{C}_{0} \text { (mg/lit) } \\
\end{array}$ & $\begin{array}{c}\text { Amount of } \\
\text { adsorbent, } \\
\text { W (gm) } \\
\end{array}$ & $\begin{array}{c}\text { Amount of adsorbate } \\
\text { adsorbed per unit amount } \\
\text { of adsorbent, } \mathrm{q}_{\mathrm{e}}(\mathrm{mg} / \mathrm{gm})\end{array}$ & $\begin{array}{c}\text { \% removal } \\
\text { of adsorbate }\end{array}$ \\
\hline \multirow{5}{*}{$\begin{array}{c}\text { Bromocresol } \\
\text { Red }\end{array}$} & 1000 & 2 & 39 & 78 \\
\hline & 1000 & 4 & 21.5 & 86 \\
\hline & 1000 & 6 & 14.91667 & 89.5 \\
\hline & 1000 & 8 & 11.5625 & 92.5 \\
\hline & 1000 & 10 & 9.375 & 93.75 \\
\hline \multirow[b]{5}{*}{ Alizarin Red } & 100 & 2 & 3.85 & 77 \\
\hline & 100 & 4 & 2.188 & 87.5 \\
\hline & 100 & 6 & 1.576 & 94.58 \\
\hline & 100 & 8 & 1.224 & 97.92 \\
\hline & 100 & 10 & 0.988 & 98.75 \\
\hline \multirow{7}{*}{$\begin{array}{c}\text { Malachite } \\
\text { Green }\end{array}$} & 500 & 0.5 & 98.75 & 98.75 \\
\hline & 500 & 1 & 49.583 & 99.17 \\
\hline & 500 & 1.5 & 33.056 & 99.17 \\
\hline & 500 & 2 & 24.844 & 99.38 \\
\hline & 500 & 2.5 & 19.875 & 99.38 \\
\hline & 500 & 3 & 16.597 & 99.58 \\
\hline & 500 & 4 & 12.448 & 99.58 \\
\hline \multirow{5}{*}{$\begin{array}{l}\text { Methylene } \\
\text { Blue }\end{array}$} & 500 & 1 & 48.464 & 96.93 \\
\hline & 500 & 1.5 & 33.021 & 99.06 \\
\hline & 500 & 2 & 24.974 & 99.9 \\
\hline & 500 & 2.5 & 19.99 & 99.95 \\
\hline & 500 & 3 & 16.667 & 100 \\
\hline
\end{tabular}




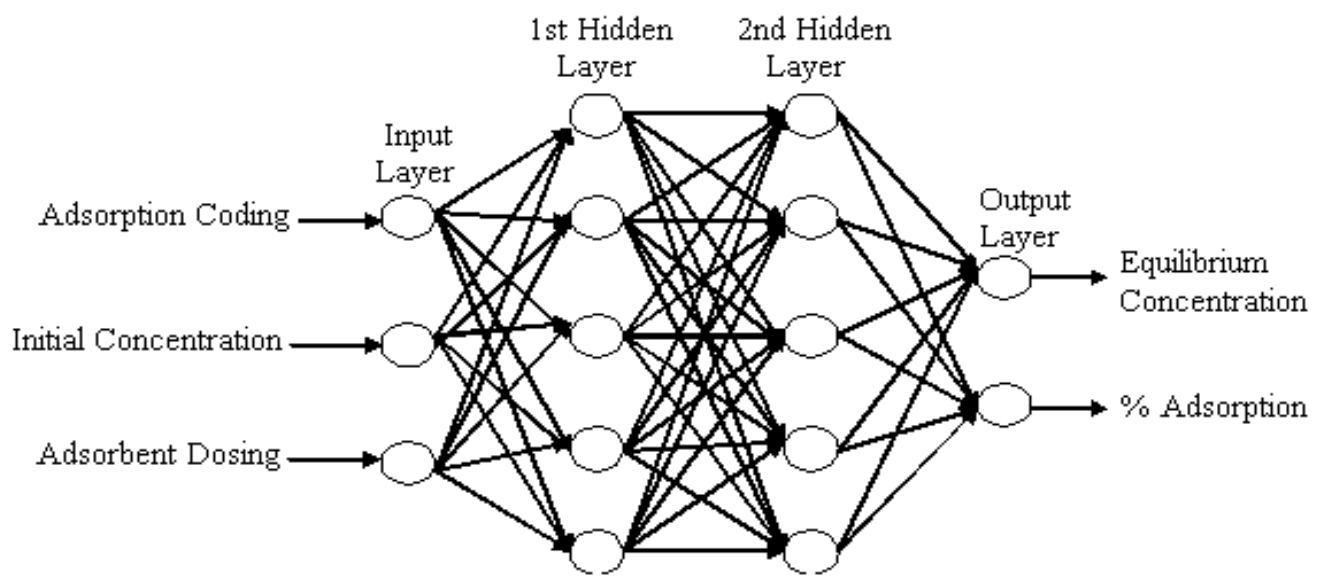

Figure 1: Artificial Neural Network Architecture

Table 2: Neural network topology for ANN model using elite-ANN

\begin{tabular}{|c|c|c|c|c|c|c|}
\hline \multicolumn{4}{|c|}{ Number of Neurons } & \multicolumn{2}{c|}{ Data Points } & $\begin{array}{c}\text { Learning } \\
\text { rate }\end{array}$ \\
\hline Input parameters & $\begin{array}{c}2^{\text {nd }} \text { hidden } \\
\text { layer }\end{array}$ & $\begin{array}{c}3^{\text {rd }} \text { hidden } \\
\text { layer }\end{array}$ & $\begin{array}{c}\text { Output } \\
\text { parameters }\end{array}$ & Training & Test & \\
\hline 3 & 05 & 05 & 2 & 18 & 4 & 0.3 \\
\hline $\begin{array}{l}\text { Iteration termination }=212380 \\
\text { Time in milliseconds }=26473\end{array}$ & $\begin{array}{l}\text { First momentum factor }=0.75 \\
\text { Second momentum factor }=0.01\end{array}$ & $\begin{array}{l}\text { RMSE for training data }=0.025 \\
\text { RMSE for test data = 0.024 }\end{array}$ \\
\hline $\begin{array}{l}\text { Input Parameters: Adsorption Coding, Initial Concentration, } \\
\text { Adsorbent Dosing }\end{array}$ & $\begin{array}{l}\text { Output Parameters: Equilibrium } \\
\text { Concentration, \% Adsorption }\end{array}$ \\
\hline
\end{tabular}

Table 3: Actual and predicted values for training data set

\begin{tabular}{|c|c|c|c|c|c|c|}
\hline $\begin{array}{c}\text { 1th } \\
\text { Input }\end{array}$ & 2th Input & 3th Input & $\begin{array}{c}\text { 1th Actual } \\
\text { output }\end{array}$ & $\begin{array}{c}\text { 1th Predicted } \\
\text { output }\end{array}$ & $\begin{array}{c}\text { 2th Actual } \\
\text { output }\end{array}$ & $\begin{array}{c}\text { 2th Predicted } \\
\text { output }\end{array}$ \\
\hline $\begin{array}{c}\text { Adsorbate } \\
\text { coding }\end{array}$ & $\begin{array}{c}\text { Initial } \\
\text { concentration, } \\
\mathbf{C}_{\mathbf{0}} \text { (mg/lit) }\end{array}$ & $\begin{array}{c}\text { Amount of } \\
\text { adsorbent, } \\
\text { W (gm) }\end{array}$ & $\begin{array}{c}\text { Equilibrium adsorption of } \\
\text { adsorbate per unit amount } \\
\text { of adsorbent, qu (mg/gm) }\end{array}$ & \multicolumn{2}{|c|}{ \% adsorption } \\
\hline 30 & 1000 & 2 & 39 & 39.8108 & 78 & 77.53448 \\
\hline 30 & 1000 & 4 & 21.5 & 20.9445 & 86 & 87.845 \\
\hline 30 & 1000 & 6 & 14.91667 & 13.8035 & 89.5 & 88.67972 \\
\hline 30 & 1000 & 10 & 9.375 & 8.67525 & 93.75 & 93.05009 \\
\hline 60 & 100 & 2 & 3.85 & 3.35197 & 77 & 76.97116 \\
\hline 60 & 100 & 4 & 2.188 & 2.44731 & 87.5 & 88.44251 \\
\hline 60 & 100 & 6 & 1.576 & 1.29069 & 94.58 & 95.99177 \\
\hline 60 & 100 & 10 & 0.988 & 0.8081 & 98.75 & 98.13324 \\
\hline 80 & 500 & 0.5 & 98.75 & 90.6463 & 98.75 & 97.93034 \\
\hline 80 & 500 & 1 & 49.583 & 53.5985 & 99.17 & 99.67745 \\
\hline 80 & 500 & 1.5 & 33.056 & 31.0649 & 99.17 & 99.86529 \\
\hline 80 & 500 & 2 & 24.844 & 23.2317 & 99.38 & 99.91076 \\
\hline 80 & 500 & 3 & 16.597 & 17.5797 & 99.58 & 99.93993 \\
\hline 80 & 500 & 4 & 12.448 & 15.1463 & 99.58 & 99.95159 \\
\hline 90 & 500 & 1 & 48.464 & 48.5422 & 96.93 & 99.76813 \\
\hline 90 & 500 & 2 & 24.974 & 22.3709 & 99.9 & 99.92453 \\
\hline 90 & 500 & 2.5 & 19.99 & 19.4598 & 99.95 & 99.93798 \\
\hline 90 & 500 & 3 & 16.667 & 17.802 & 100 & 99.94555 \\
\hline
\end{tabular}


Table 4: Actual and predicted values for test data set

\begin{tabular}{|c|c|c|c|c|c|c|}
\hline $\begin{array}{c}\text { 1th } \\
\text { Input }\end{array}$ & 2th Input & 3th Input & $\begin{array}{c}\text { 1th Actual } \\
\text { output }\end{array}$ & $\begin{array}{c}\text { 1th Predicted } \\
\text { output }\end{array}$ & $\begin{array}{c}\text { 2th Actual } \\
\text { output }\end{array}$ & $\begin{array}{c}\text { 2th Predicted } \\
\text { output }\end{array}$ \\
\hline $\begin{array}{c}\text { Adsorbate } \\
\text { Coding }\end{array}$ & $\begin{array}{c}\text { Initial } \\
\text { concentration, } \\
\mathbf{C}_{\mathbf{0}} \text { (mg/lit) }\end{array}$ & $\begin{array}{c}\text { Amount of } \\
\text { adsorbent, } \\
\mathbf{W}(\mathbf{g m})\end{array}$ & \multicolumn{2}{|c|}{$\begin{array}{c}\text { Equilibrium adsorption of } \\
\text { adsorbate per unit amount of } \\
\text { adsorbent, }\end{array}$} & \multicolumn{2}{|c|}{ (mg/gm) } \\
\hline 30 & 1000 & 8 & 11.5625 & 10.55648 & 92.5 & 90.38971 \\
\hline 60 & 100 & 8 & 1.224 & 1.35749 & 97.92 & 97.90939 \\
\hline 80 & 500 & 2.5 & 19.875 & 19.64398 & 99.38 & 99.9296 \\
\hline 90 & 500 & 1.5 & 33.021 & 28.87818 & 99.06 & 99.89282 \\
\hline
\end{tabular}

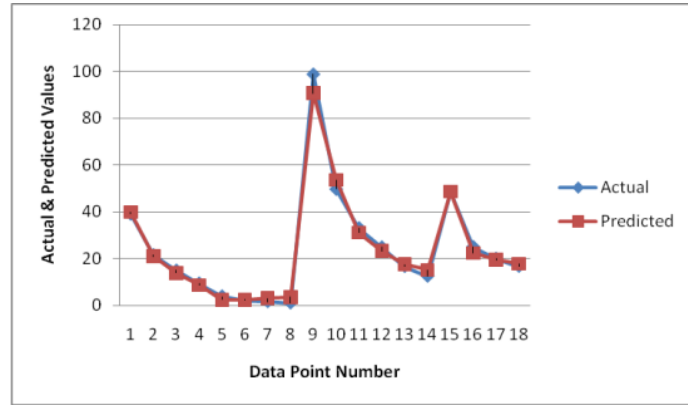

Figure 2: Comparison of actual and predicted values of equilibrium concentration of adsorbates for training data set

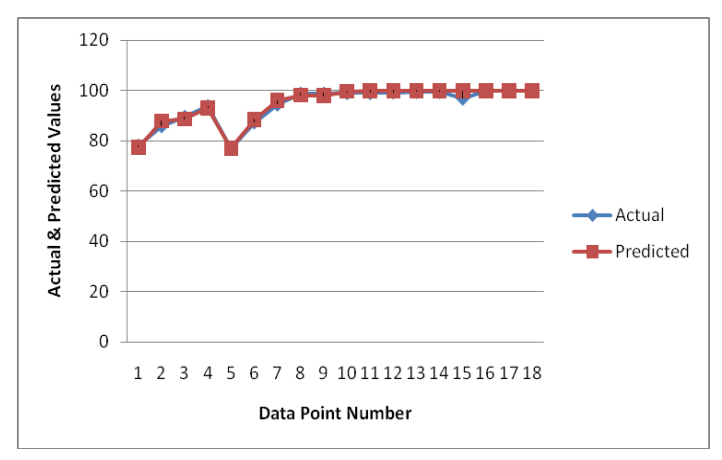

Figure 3: Comparison of actual and predicted values of \% adsorption of adsorbates for training data set

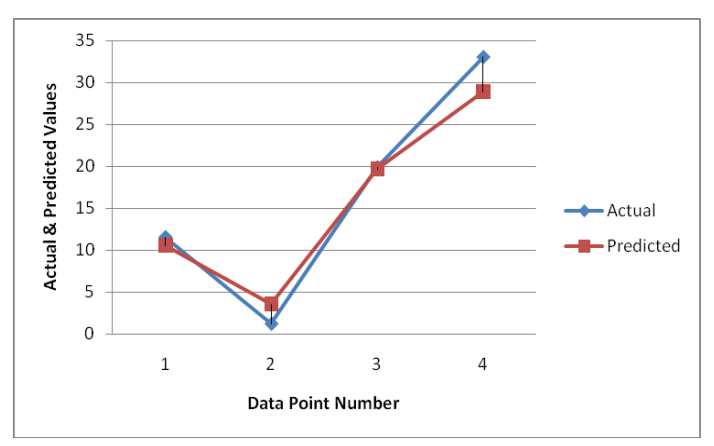

Figure 4: Comparison of actual and predicted values of equilibrium concentration of adsorbates for test data set

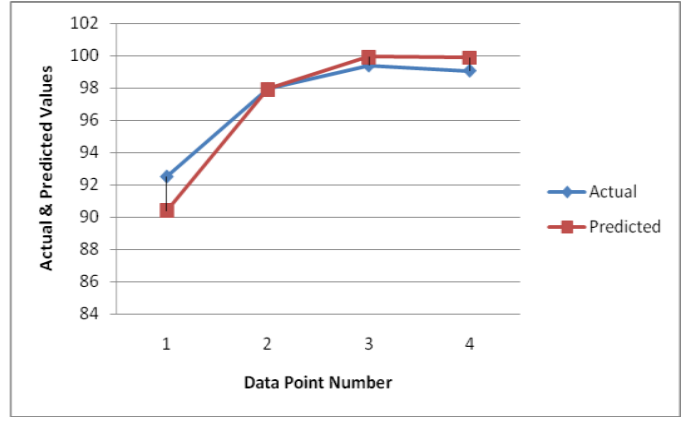

Figure 5: Comparison of actual and predicted values of \% adsorption of adsorbates for test data set

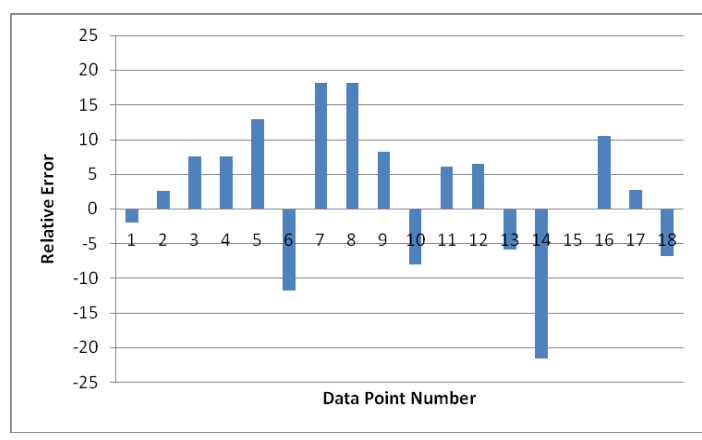

Figure 6: \% Relative error for equilibrium concentraiton of adsorbates for training data set

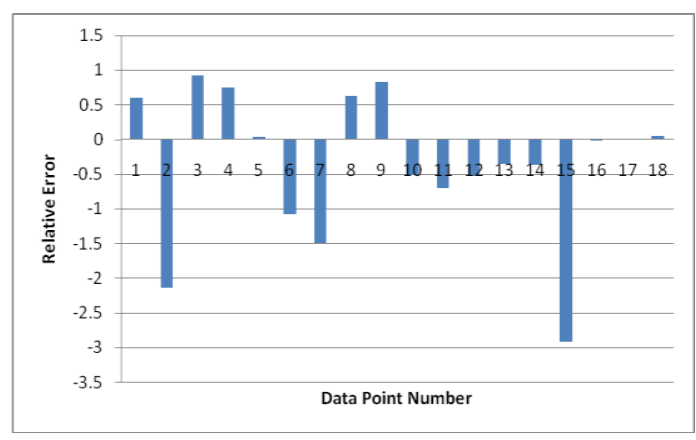

Figure 7: \% Relative error for \% adsorption of adsorbates for training data set 


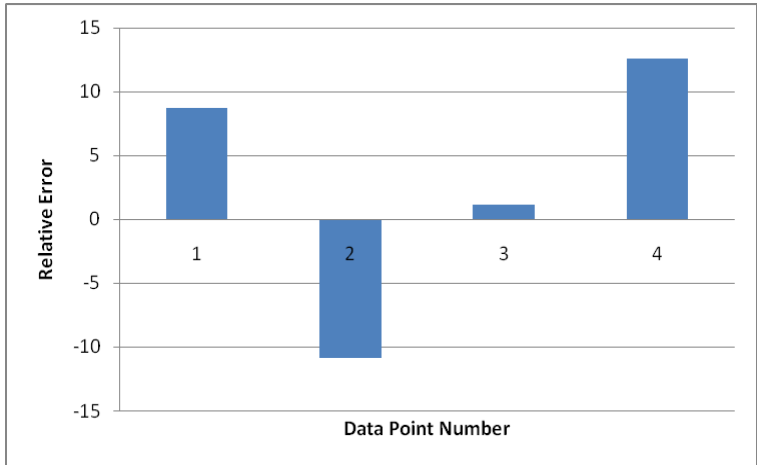

Figure 8: \% Relative error for equilibrium concentraiton of adsorbates for test data set

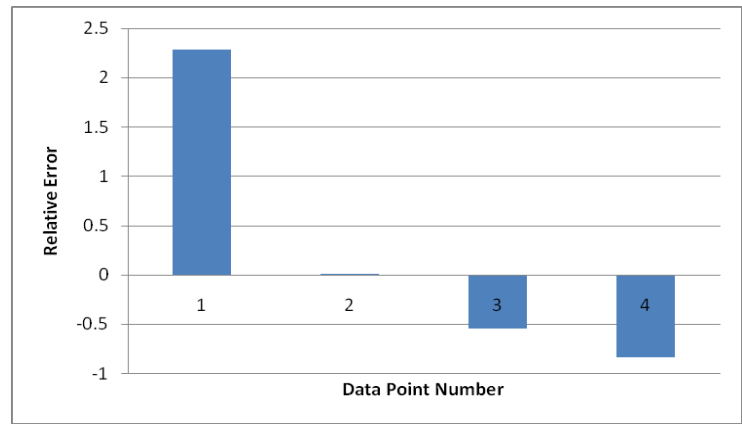

Figure 9: \% Relative error for \% adsorption of adsorbates for test data set

\section{RESULTS \& DISCUSSION}

The yield of rice husk carbon (RHC) synthesized in present work is $50 \%$ having surface area of $208.637 \pm 3.4941 \mathrm{~m}^{2} / \mathrm{gm}$ as determined by BET analyzer.

The comparison of actual and predicted values of equilibrium concentration and \% adsorption of various adsorbates like bromocresol red, alizarin red, malachite green and methylene blue have been plotted as shown in figure 2 and figure 3 for training data set; and figure 4 and figure 5 for test data set. As can be seen from these graphs, actual and predicted values are very close to each other. However for substantiating the claim of accuracy of prediction further, relative error have been calculated plotted as shown in figure 6 and figure 7 for training data set and figure 8 and figure 9 for test data set.

\section{CONCLUSION}

It can be concluded that the ANN model developed has excellent accuracy and the model can be effectively used for prediction of $\%$ adsorption and equilibrium concentration of dyes on rice husk carbon adsorbent. The unique feature of the ANN model developed is that it gives substitute for conventional adsorption isotherm that enables the user to incorporate the multiple adsorbates in the same correlation with ease $\&$ high accuracy. The work is demonstrative $\&$ can be extended for more combinations of adsorbate $\&$ adsorbent in a single ANN model.

\section{REFERENCES}

[1] Wenping Li, Carl Berthold, Carl Kiser and Quintin Richard, August 2009, MaxFlo,Agrilectric Research Company, USA

[2] Wenping Li, Carl Kiser, Quintin Richard, ,Agrilectric Research Company, USA, 2009, Paper presented at the American Filtration \& Separations Society, 2005 International Topical Conferences \& Exposition

[3] Ola Abdelwahab, Ahmed El Nemr, Amany El Sikaily and Azza Khaled, 2005, Egyptian Journal of Aquatic Research, Vol. 31 (1)

[4] Y.C. Sharma, B. Singh and Uma, 2009, The Open Environmental Pollution \& Toxicology Journal, Vol. 1, $74-78$

[5] F. A. Adekola and H.I. Adegoke, 2005, Zfe Journal of Science, Vol. 7 (1)

[6] Anderson J.A, 1999, An Introduction to Neural Networks (Prentice-Hall of India, Pvt. Ltd., New Delhi)

[7] Rumelhart D E \& McClleland, 1986, Back Propagation Training Algorithm Processing, M.I.T Press, Cambridge Massachusetts

[8] Fan J Y, Nikolau M \& White R E, 1993, AIChE, 39 (1), 82

[9] Hoskins J C, Kaliyur K M \& Himmelblau D M, 1991, AIChE, 37(1), 137

[10] Watanabe K, Abe M, Kubota M \& Himmelblau D M, 1989, AIChE, 35 (11), 1803

[11] Balsitor B \& Banergy S, 1998, AIChE 44 (12), 2675

[12] Pandharipande S L \& Badhe Y P, 2003, Chem Eng World 38(6), 70

[13] Zamankhan P, Malinen P \& Lepomaki H, 1997, AIChE, 43(7), 1684

[14] Baratti R, Vacca G \& Servida A, 1995, Hydrocarbon Processing, 35

[15] Pandharipande S L, Agarwal R S, Gogte B B \& Badhe Y P, 2003, Chem Eng World 38 (5), 78

[16] Pandharipande S L \& Badhe Y P, 2003, Chem Eng World $38(8), 82$

[17] Pandharipande S L \& Badhe Y P, 2003, IIChe, 45(4), 256

[18] Pandharipande S L \& Mandavgane S A, 2004, Indian J Chem Technol, 11 (6), 820

[19] Pandharipande S L, Bhaise A \& Poharkar A, 2004, Chem Eng world, 39 (1), 50

[20] Pandharipande S L \& Badhe Y P, 2004, J Inst Eng, 84 (3), 65

[21] Pandharipande S L \& Badhe Y P, elite-ANN software, copyright ROC-SW-1471-2004 